\title{
Investigation of symptom free patients after myocardial infarction
}

\author{
CLIVE E HANDLER \\ From the Department of Cardiology, Guy's Hospital, London
}

\begin{abstract}
The identification of patients at high risk of subsequent cardiac events after myocardial infarction has been a topic of considerable interest for several years. Recently its importance has been underlined by the results of trials of early $\beta$ blockade after infarction ${ }^{1}$ and of the feasibility and potential value of early myocardial revascularisation by coronary artery bypass operation and percutaneous transluminal coronary angioplasty. ${ }^{2-4}$ Although these procedures are beneficial to certain subgroups of patients with stable angina and coronary artery disease, ${ }^{5}$ their value to high risk survivors of infarction remains to be established. Nevertheless, patients who appear to be at high risk from cardiac death, another infarct, or angina are considered in many centres for coronary angiography and secondary prevention treatments. Conversely, those who are symptom free and those identified as being at relatively low risk are usually reassured and not considered for expensive invasive investigations unless they are young.
\end{abstract}

\section{METHODS TO ASSESS PROGNOSIS AFTER MYOCARDIAL INFARCTION}

Outcome after infarction depends chiefly on residual left ventricular function, but the extent of coronary artery disease, residual myocardial ischaemia, and ventricular arrhythmias may also be important. ${ }^{6-8}$ Clinical examination, ${ }^{9}$ chest $x$ rays, and serial electrocardiograms provide crude but useful estimations of the extent of myocardial damage. Additional prognostic information may be gleaned from exercise testing, thallium myocardial scintigraphy, gated radionuclide left ventriculography, echo-

Requests for reprints to Dr Clive E Handler, Department of Cardiology, Guy's Hospital, St Thomas Street, London SE1 9RT. cardiography, and Holter monitoring. The use of only one method for risk stratification after infarction may be misleading. At present, exercise testing and radionuclide left ventriculography are probably the most widely used and valuable noninvasive investigations and they provide complementary information on residual reversible myocardial ischaemia and left ventricular function.

NON-INVASIVE DIAGNOSIS OF MULTIVESSEL CORONARY ARTERY DISEASE IN SYMPTOM FREE PATIENTS AFTER INFARCTION

Others have investigated the potential of exercise testing for the early identification of multiple vessel disease in patients with uncomplicated myocardial infarction. ${ }^{10}$ In this issue of the British Heart fournal Fubini et al (p 535) compare the value of exercise testing with that of radionuclide angiography in the detection of multivessel coronary artery disease after a first uncomplicated myocardial infarction in symptom free patients. ${ }^{11}$ Their results indicate that maximal treadmill exercise testing does not reliably detect residual myocardial ischaemia, and instead they advocate the use of radionuclide angiography, particularly left ventricular ejection fraction response and the standard deviation of the phase histogram. Fubini et al conclude that multiple vessel coronary artery disease can be effectively excluded when both of these radionuclide measurements are normal.

\section{RATIONALE FOR DIAGNOSIS OF ISCHAEMIA AFTER INFARCTION}

The study raises some interesting points. The first centres on the rationale for performing coronary angiography and other investigations in symptom free patients after infarction to assess the presence of 
coronary artery disease. This is a complex issue and has financial and logistic implications. The purpose of exercise testing and radionuclide studies in patients after infarction is not, as in those with suspected ischaemic heart disease, to confirm or exclude the presence of coronary artery disease since the pretest likelihood of this is virtually $100 \%$. The presence (and therefore accurate identification) of multivessel coronary artery disease only becomes clinically relevant if it influences prognosis and if myocardial revascularisation is shown to be beneficial in these subjects, an appreciable number of whom will be symptom free. Although there is some evidence that both an abnormal left ventricular ejection fraction in response to exercise ${ }^{12}$ and the extent of a thallium perfusion defect ${ }^{13}$ are important predictors of future cardiac events in patients with coronary artery disease, the value of myocardial revascularisation in symptom free patients is unclear. Therefore, at present, there is little evidence to support the routine practice of coronary angiography in symptom free survivors of uncomplicated infarction.

\section{PREDICTIVE VALUE OF NON-INVASIVE}

INVESTIGATIONS IN SYMPTOM FREE PATIENTS AFTER INFARCTION

The results from the study of Fubini $e t$ al should be looked at in the light of Bayesian analysis. ${ }^{14}$ Studies assessing the prognostic value of exercise testing, thallium myocardial scintigraphy, and radionuclide angiography early after infarction have usually assessed the predictive value of abnormal test results. Because the incidence of serious cardiac events in patients suitable for maximal postinfarction stress testing is rather low, ${ }^{71516}$ the predictive accuracy of an abnormal test result will be correspondingly low. Because the prevalence of multivessel coronary artery disease in survivors of infarction varies from $30 \%$ to $50 \%$ the predictive accuracy of tests assessing the presence of multivessel disease will also be low. The predictive accuracy of a normal test, however, as reported by Fubini et al, will be very high.

Classifying an exercise test response as either "positive" or "negative" on the basis of the ST segment response alone, as they did, is open to criticism. ${ }^{17}$

\section{False positives}

Discrepancies between the results of anatomical assessments of coronary artery disease (coronary angiography) and physiological evaluations of myocardial ischaemia (exercise testing and myocardial scintigraphy) are often difficult to reconcile. It is possible that some of the "false positive" responses in the patients studied by Fubini and coworkers did truly reflect myocardial ischaemia that was present despite the absence of angiographically demonstrable (or that defined as important) coronary artery disease. Such disturbances to coronary artery flow may be explained by a dynamic rather than by a fixed obstructive stenosis. ${ }^{18}$ This is a complex issue because if a "false" positive exercise response can indicate ischaemia and if residual ischaemia is prognostically important, a "false" positive response should also be prognostically important even in symptom free patients. Epidemiological studies, however, indicate that the chance of a cardiac event occurring in this patient subset is small. ${ }^{19}$

\section{False negatives}

Fubini et al also found that an appreciable number of patients with multivessel disease had a negative ST segment response. False negative results were more common in patients with anterior infarcts and this phenomenon is well recognised. Patients with $\mathbf{Q}$ waves extending across the chest leads of the electrocardiogram often have associated ST segment elevation that may persist for several months after infarction. Exercise in these subjects almost invariably results in further ST segment elevation in these leads, particularly early after infarction, and this response appears to be influenced chiefly by the site and type of infarction ${ }^{20}$ and has independent prognostic importance. ${ }^{8}$ The mechanism of ST elevation during exercise is obscure, but reversible ischaemia $^{21}$ and underlying left ventricular dyskinesia are likely factors. It has been proposed that a dyskinetic segment may generate forces opposing the ischaemic vector and hence a spuriously low sensitivity of the exercise test in detecting multivessel disease. ${ }^{22}$ The results of further studies addressing this problem are awaited with interest.

\section{RADIONUCLIDE ASSESSMENT OF MULTIVESSEL DISEASE}

Radionuclide angiography is probably the most convenient method of assessing ejection fraction and regional and global left ventricular function. It is widely available in Britain, but performing and interpreting the results of the scans require experience and considerable technical expertise. The presence of residual reversible myocardial ischaemia after infarction causes global and regional changes in ventricular function. The two most commonly used criteria of abnormality are failure of the ejection fraction response to exercise to increase by at least $5 \%$ or the development of regional wall motion abnormalities during exercise. These criteria are, however, non-specific for coronary artery disease.

Phase analysis refers to a group of methods used 
to produce functional or parametric images from radionuclide ventriculograms. A mathematical function (usually sinusoidal) is fitted to the time/activity curve of each pixel in the angiocardiogram. The phase of the fitted function, that is the interval between the $R$ wave trigger and the maximum value of the function, and the amplitude of the function, that is half the difference between its maximum and minimum values, are taken as indices of the timing and magnitude of cardiac wall motion respectively in the region of the pixel. Phase analysis is subject to statistical and physiological factors but might demonstrate ventricular asynchrony resulting from exercise induced ischaemia. It provides objective information on the timing of regional left ventricular wall movement.

The standard deviation of the left ventricular phase histogram has been shown in some studies to provide useful diagnostic information in patients with coronary artery disease ${ }^{23}$ but other reports have found it to be of little or no value and recommend the use of skewness (asymmetry) of the left ventricular phase histogram during maximum exercise because of its greater specificity. ${ }^{24}$ In general it is advisable to assess the raw phase image together with the phase histogram particularly when two areas of the left ventricle are suspected to be abnormal.

The sensitivity and specificity of radionuclide left ventriculography are also influenced appreciably by the site of infarction and ischaemia. Counts are attenuated from the inferior wall of the left ventricle and so the radionuclide angiogram is less sensitive when this area is assessed. A left posterior oblique view may help to resolve this difficulty.

Few centres in the United Kingdom routinely use an analysis of the standard deviation of the phases of the left ventricular histogram, but this approach may be of value in selected patients. Further analyses of this approach in symptom free patients after infarction would be of interest.

\section{TEMPORAL CHANGES IN CORONARY ARTERY \\ ANATOMY}

A long interval between non-invasive tests of myocardial ischaemia and coronary angiography may introduce confounding variables to studies relating these investigations. Bruscke $e t a^{25}$ were among the first to draw attention to the progression of coronary artery disease that occurs more frequently at certain sites. ${ }^{26}$ Since then others have confirmed this finding and have also found corresponding changes in left ventricular function. ${ }^{27}$ Fubini and colleagues have carefully avoided this problem by performing the two investigations within two weeks of each other.
CLINICAL IMPLICATIONS

The most appropriate management of symptom free patients after myocardial infarction remains illdefined. Whether a rigorous assessment of additional coronary artery disease and residual reversible myocardial ischaemia should be undertaken in this group of patients, who appear to have a good prognosis, remains to be established.

Bonow and colleagues found that mildly symptomatic patients with three vessel coronary artery disease and preserved left ventricular function who developed exercise induced ST segment depression and a decrease in radionuclide left ventricular ejection fraction and who also had impaired exercise tolerance were at high risk from cardiac death and heart failure. ${ }^{12}$ Patients with three vessel coronary artery disease but without signs of inducible ischaemia or deterioration in left ventricular function during exercise had an excellent prognosis. If these findings are shown to be relevant to asymptomatic or mildly symptomatic patients after infarction, it may be argued that a large proportion of survivors of infarction may have to have further expensive and currently scarce investigations on the assumption that those at high risk may benefit from myocardial revascularisation. There is, however, no convincing evidence that prognosis in this group of patients with multivessel coronary artery disease is improved by specific medical treatment or myocardial revascularisation. Further investigations are thus probably only indicated when symptoms develop. The threshold for investigation and coronary angiography is usually lowered if a patient is young, has cardiac risk factors, and when there is a family history of ischaemic heart disease. The optimum management of these special subjects is also controversial.

I am grateful to Dr Richard Underwood and to Dr Edward Baker for their help in the preparation of this paper.

\section{References}

1 Norwegian Multicenter Study Group. Timololinduced reduction in mortality and reinfarction in patients surviving acute myocardial infarction. $N$ Engl $\boldsymbol{f}$ Med 1981; 304: 801-7.

2 Norris RM, Agnew TM, Brandt PWT, et al. Coronary surgery after recurrent myocardial infarction. prognosis of a trial comparing surgical with non surgical management for asymptomatic patients with advanced coronary disease. Circulation 1981; 63: 785-92.

3 Dodge HT, Sheehan FH, Mathey DG, Brown BG, Kennedy JW. Usefulness of coronary artery bypass 
graft surgery or percutaneous transluminal angioplasty after thrombolytic therapy. Circulation 1985; 72 (suppl V): V39-45.

4 Singh AK, Rivera R, Cooper GN, Karlson KE. Early myocardial revascularization for postinfarction angina: results and long-term follow-up. $\mathcal{F}$ Am Coll Cardiol 1985; 6: 1121-5.

5 European Coronary Surgery Study Group. Prospective randomised study of coronary artery bypass surgery in stable angina pectoris. Lancet 1980; ii: 491-5.

6 The Multicenter Postinfarction Research Group. Risk stratification after myocardial infarction. $N$ Engl $\mathcal{F}$ Med 1983; 309: 331-6.

7 Theroux P, Waters DD, Halphen C, Debaisieux J-C, Mizgala HF. Prognostic value of exercise testing soon after myocardial infarction. $N$ Engl f Med 1979; 301: 341-5.

8 Handler CE. Submaximal predischarge exercise testing after myocardial infarction: prognostic value and limitations. Eur Heart $\mathcal{7}$ 1985; 6: 510-7.

9 Killip T, Kimball JT. Treatment of myocardial infarction in a coronary care unit. A two year experience with 250 patients. Am $\mathcal{F}$ Cardiol 1967; 20: 457-64.

10 Akras F, Upward J, Jackson G. Early exercise testing and coronary angiography after uncomplicated myocardial infarction. $\mathrm{Br}$ Med $\mathcal{3}$ 1982; 284: 1293-4.

11 Fubini A, Cecchi E, Spinnler MT, et al. Use of radionuclide angiography and an electrocardiographic stress test to diagnose multivessel disease after a first episode of uncomplicated myocardial infarction. Br Heart $\mathcal{f}$ 1986; 55: 535-42.

12 Bonow RO, Kent KM, Rosing DR, et al. Exerciseinduced ischemia in mildly symptomatic patients with coronary artery disease, and preserved left ventricular function: identification of sub-groups at high risk for death during medical therapy. $N$ Engl $f$ Med 1984; 311: 1339-45.

13 Iskandrian AS, Hakki AH, Kane-Marsch S. Prognostic implications of exercise Thallium-201 scintigraphy in patients with suspected or known coronary artery disease. Am Heart f 1985; 110: 135-43.

14 Diamond GA, Forrester JS. Analysis of probability as an aid in the clinical diagnosis of coronary artery disease. $N$ Engl f Med 1979; 300: 1350-8.

15 Fioretti P, Brower RW, Simoons ML, et al. Prediction of mortality in hospital survivors of myocardial in- farction. Comparison of predischarge exercise testing and radionuclide ventriculography at rest. $\mathrm{Br}$ Heart $\mathcal{F}$ 1984; 52: 292-8.

16 Waters DD, Bosch X, Bouchard A, et al. Comparison of clinical variables and variables derived from a limited predischarge exercise test as predictors of early and late mortality after myocardial infarction. $\mathcal{f} \mathrm{Am} \mathrm{Coll} \mathrm{Cardiol}$ 1985; 5: 1-8.

17 Redwood DR, Borer JS, Epstein SE. Whither the ST segment during exercise? Circulation 1976; 54: 703-6.

18 Epstein SE, Talbot TL. Dynamic coronary tone in precipitation, exacerbation and relief of angina pectoris. Am $\mathcal{f}$ Cardiol 1981; 48: 797-803.

19 Bruce RA, McDonough JR. Stress testing in screening for cardiovascular disease. Bull NY Acad Med 1969; 45: 1288-305.

20 Handler CE, Sowton E. Exercise induced ST elevation post-infarction: prognostic importance and relation to site of infarct [Abstract]. Br Heart F 1985; 54: 646-7.

21 Fox KM, Jonathan A, Selwyn A. Significance of exercise induced ST elevation in patients with previous myocardial infarction. Br Heart $\mathcal{F}$ 1983; 49: 15-9.

22 Castellanet MJ, Greenberg PS, Ellestad MH. Comparison of ST segment changes on exercise testing with angiographic findings in patients with prior myocardial infarction. Am $\mathcal{F}$ Cardiol 1978; 42: 29-35.

23 Ratib O, Henze E, Schön H, Schelbert HR. Phase analysis of radionuclide ventriculograms for the detection of coronary artery disease. Am Heart $\mathcal{F}$ 1982; 104: 1-12.

24 Turner DA, Shima MA, Ruggie N, et al. Coronary artery disease: detection by phase analysis of rest/exercise radionuclide angiocardiograms. Radiology 1983; 148: 539-45.

25 Bruscke AVG, Proudfit WL, Sones FM Jr. Clinical course of patients with normal, and slightly or moderately abnormal coronary arteriograms. A follow up study on 500 patients. Circulation 1973; 57: 936-45.

26 Bruscke AVG, Wijers TS, Kolsters W, Landmann J. The anatomic evolution of coronary artery disease demonstrated by coronary arteriography in 256 nonoperated patients. Circulation 1981; 63: 527-36.

27 Kramer JR, Kitazume H, Proudfit WL, Matsuda Y, Williams GW, Sones MF. Progression and regression of coronary atherosclerosis: relation to risk factors. $\mathrm{Am}$ Heart $\mathcal{F}$ 1983; 105: 134-44. 